\title{
Influence of the Principal's Digital Leadership on the Reflective Practices of Vocational Teachers Mediated by Trust, Self Efficacy, and Work Engagement
}

\author{
Rini Agustina ${ }^{1}$ and Waras Kamdi \\ State University of Malang, Malang, East Java, Indonesia \\ 1https:// orcid.org/0000-0003-1650-4994 \\ Syamsul Hadi, Muladi and Didik Nurhadi \\ State University of Malang, Malang, East Java, Indonesia \\ https:// orcid.org/0000-0003-1220-2729 \\ https:// orcid.org/0000-0002-2904-5398 \\ https://orcid.org/0000-0002-6365-535X
}

\begin{abstract}
This study aims to determine the effect of the principal's digital leadership on vocational teachers' reflection practice, mediated by the variables of trust, self-efficacy, and work involvement. This study uses path analysis with modeling using SEM (AMOS). The sample of this research is 637 ( $\mathrm{N}=340$ females and $\mathrm{N}=297$ males) vocational high school teachers in Malang Raya, East Java, Indonesia. The researchers have used a purposive random sampling technique to meet the objectives of this research. The investigators have used a 86 item questionnaire to collect data on the studied variables. Based on the fit model's estimation, there is a direct and indirect relationship between the five variables used. The variables of trust, self-efficacy, and job involvement contributed significantly to intervening variables. It can be concluded that the moderating variable strengthens the framework for the relationship between digital leadership and teacher reflective practices. The new relationship formed is a direct contribution of digital leadership to work engagement with a magnitude of 0.120 and a direct relationship made between digital leadership and the reflective practice of teachers of 0.168 . This relationship has a positive impact on teacher actions. These results indicate that the teacher appreciates the Principal's leadership, who both supports facilitates the learning process in using technology in the learning process. Moreover, teachers feel motivated and excited to reflect on their learning because of the leaders who have digital characters. The teacher considered leaders with digital personalities more open and tended to free them to manage the class.
\end{abstract}

Keywords: digital leadership; trust; self-efficacy; work engagement; teacher eflective practice 


\section{Introduction}

Professional teachers always reflect on their work practices by thinking slowly about the problems they face in their professional life (Beetham \& Sharpe, 2013). In other words, experienced teachers must be reflective practitioners (Zhong, 2017). The reflective practitioner is a very complex ability that includes the potential to reflect on actions as part of the learning process on an ongoing basis ( Zhong, 2016). Having reflective abilities is not easy because teachers are always required to pay attention to their students, starting from learning, methods used, effective teaching methods, and how to assess their students. Taking into consideration students' living environment and their parents are another fundamental resources instructors need to call for. Such a notion reflects how worthiness reflective teaching is and the unseen realities it covers.

In this respect, teachers' reflective practices is successful when administrators of prospective teacher education programs work as a reflective practitioner to focus on education performance (Nie, 2015; Zhong, 2017). The need for selfdevelopment skills as reflective practitioners will be more significant for vocational teachers who are tasked with developing student potential related to companies and industry (Minghui, Lei, Xiaomeng \& Potmešilc, 2018; Nie, Lau \& Liau, 2012).

With regard to the above mentioned, teachers cannot fend for themselves but need the principal's support, which is one of the driving forces in shaping teacher character and is an essential factor determining school effectiveness (Minghui et al., 2018). In other terms, leaders act as role models for the school community they lead and are a factor in strategies for increasing learning effectiveness(Reza $\&$ Sarab, 2016). Factors that are thought to influence teachers in the knowledge reflection process are teacher self-efficacy (Want et al., 2019), trust (Osifo, 2016), and work engagement (Drewniak \& Karaszewski, 2016; Engelbrecht, Heine \& Mahembe, 2017; Men, 2015). Leadership factors and internal teachers' factors are the focus of this study because they are closely related in fostering and forming teacher reflection practices in their learning.

Although there is a lot of research on leadership and its influence on teachers and the learning process, its basic principles are still needed so that schools can be called successful. researchers still try to reveal the other side of leadership regarding their understanding of digital technology since the latter offers new opportunities and challenges for organizations and society (Niekerk, 2015; Niekerk \& Wyk, 2014). More than that, digital leaders must keep up with the global revolution that is taking place (Richardson, Bathon, Flora, \& Lewis, 2012) since it takes a dynamic combination of mindset, behaviour, and skills to change and/or enhance the school culture. Always, changing times and people's dependence on technology demands an evolution of leadership practices to create schools that can adapt to technological developments(Mok \& Moore, 2019).

Therefore, leadership is an important factor in the success of the educational process and goals. As highlighted in the above paragraph, leadership is a combination of skills and character to influence and encourage others to work 
effectively and below expectations (Kalkan, Aksal, Gazi, Atasoy \& Dağlı, 2020; Ünal, Uzun \& Karataş, 2015). Kamdi (2014) states that to become a vocational school teacher today is not easy because of the high workload compared to nonvocational teachers. The competence of vocational teachers must keep abreast of the job market dynamics because they are related to industrial developments. Increasing the competence of vocational teachers has a faster expiry rate than non-vocational teachers' skills. Accordingly, vocational teachers are always required to learn and, at the same time, keep up with technology transfer.

For this reason, vocational teachers must have the ability to continue to reflect on their learning for the success of education and renew their professional competencies. A strong commitment to the teacher formed from the work engagement variable is expected to increase teacher motivation to continue to reflect on their learning. Students will later catch the teacher's commitment to dynamic change in the learning system, technological changes, and the changing times that are increasingly fast. Another hope is that teachers will be able to foster the same reflective practice for their students so that they are ready to enter into the wider community.

The lack of studies on the topic of technology integration in schools and more significantly the lack of research on the role of digital leadership in creating digital cultures came to the attention of Richardson, Bathon, Flora, and Lewis, who published a NETS-A review of all literature published between 1997 and 2012 on the topic of school digital leadership. In the same context, Richardson (2012) came out with the conclusion that nearly $68 \%$ of digital leadership articles are descriptive only. That is,more scientific studies are needed on issues related to technological standards for school leaders, as well as the skills of leaders who will become change leaders. Based on Richardson's suggestion and some other references and the lack of in-depth research on this topic, this study is a review of a new type of leadership, namely digital leadership, that has never correlated with other variables related to teacher reflective practices. The gap taken in this study is the development of a research model related to digital leadership with the variables of trust, self-efficacy, and work engagement. The use of these variables is thought to foster the practice of teacher reflection. Therefore, this study aims to answer the following research questions:

1. Are there any relationships between Digital Leadership, teacher trust, efficacy, work engagement, and reflective teacher practice?

2. Do trust, self-efficacy, and work engagement become moderators of variables between digital leadership and teacher reflective practice?

\section{2. literature Review}

\subsection{Teacher's Reflective Practice}

Schön (Schön, 1983) is said to be the first who introduced the idea of a reflective practitioner, in which he claimed that reflective practice is at the core of professional knowledge and learning, in response to the limitations inherent in technical rationality models. Reflective is defined as a spontaneous and automatic response, which adopts a new thought process (Bassot, 2016). Reflective is at the core of the experiential learning model, which offers a holistic 
and integrated learning perspective combining experience, perception, cognition, and behaviour. Teachers' engagement in reflective practice is mainly influenced by the expectations obtained from previous experience, knowledge, education, age, gender, economic background, and culture(Bolton, 2015). Reflective teaching is the development of teacher professionalism with a cyclic process. According to Bassot (2016) and McCarty (2013), reflective teaching is the opportunity for teacher to explore, question, and reframe their teaching practice holistically to be interpreted based on conditions in the field.

In doing so, teachers will be informed in determining the appropriate process to improve performance. Reflective teaching will give birth to an attitude of openness (open-mindedness), full involvement (wholeheartedness), and responsibility (Bassot, 2016; Slade, Burnham, Catalana, \& Waters, 2019). Reflective teaching should not be seen as a teaching method or teaching model ,but a method that has a broader and holistic perspective. According to Reza and Sarab (2016), reflective learning include: practical; cognitive; participants; and metacognitive indicators.

\subsection{Work Engagement}

Job engagement is by definition a high level of energy and reliable identification with one's work in a positive, satisfying, and work-related state of mind characterized by enthusiasm, dedication, and absorption (Men, 2015). According to Salicru (2015), work engagement is a form of positive job fulfilment from the mind's character centre. Put differently, work engagement is a centre of motivation and positive thinking related to work, enthusiasm, dedication, and absorption. A teacher with a high work engagement to his/her job will show that $\mathrm{s} /$ he cares about the job. Work engagement is determined by persons who are physically and psychologically devoted to their work. Minghui et al. (2018) concluded that work engagement is a suggestion to work without coercion, both physically and psychologically, with enthusiasm and inner satisfaction during work. Vigor (Spirit); dedication; and absorption are claimed to be the indicators of work engagement, Men (2015).

\subsection{Teacher Self-Efficacy}

Teacher self-efficacy is the extent to which teachers believe that they can influence student engagement and learning outcomes. This relationship becomes more robust when the teacher feels no external pressure and feels determined to teach. Teachers' self-efficacy affects their persistence, the effort they invest in education, and the goals they set (Barni, Danioni \& Benevene, 2019). Self-efficacy is relevant to professional identity and teacher-student relationships (Bellingham, 2013; Farris-Berg \& Dirkswager, 2012). This research's self-efficacy is related to three teaching components: classroom management, student involvement, and teaching strategies (Miovska-Spaseva, 2016). That is to say, self-efficacy in classroom management refers to teachers' belief in developing and maintaining classroom order. Successful student engagement refers to the teacher's belief in motivating students and engaging them in their learning process. Teaching strategies' effectiveness relates to teachers' beliefs in using various pedagogical-didactic techniques in the classroom (Zee \& Koomen, 2016). 


\subsection{Teacher Trust}

Trust is the glue that binds leaders to followers and provides organizational success and leadership (Mineo, 2014). It is not a momentary event but a series of investments over time that will make success possible. Prince (2018) approaches trust as a complex, dynamic, and multidimensional phenomenon related to several essential variables regarding school organizations effectiveness, human relations, and behaviour. School leaders must take deliberate actions to ensure that relationships are built through open and active communication. In hope to achieve the aforesaid, there must be transparency in decision-making so that everything is seen as fair and in the common interest. As a result, teachers who feel trusted will try to meet the needs of their students.

Despite the fact that they are sometimes subject to feel uncomfortable in communicating with the principal, trust in teachers exists to create good interpersonal relationships in the school system. Research conducted by Osifo (2016) states that trust is a strong personal relationship between the principal and the teacher to become a school principal. Research shows that influential school leaders support their teaching staff and trust their professional judgment (Jachowicz, 2016). Developing trust is not an easy task since some challenges must be overcome, and there are always differences in opinion about the school system in terms of curriculum, teaching practice, and/or school policy (Drewniak \& Karaszewski, 2016).

\subsection{Digital Leadership}

Digitalization is essential for any organization and society. The way organizations communicate with clients, do marketing, deliver products, and run business processes is heavily influenced by digital technology. New developments in digital technology offer new opportunities and challenges for organizations and society (Loebbecke \& Schepers, 2020). When an organization fails to keep up with its competitors' use of digital technology or its clients' expectations, it may be forced to close (McKeown, 2015). If society fails to absorb new communication opportunities, information sharing, and cooperation, the community is vulnerable to chaos and dysfunctional social structures. Leaders must point the way forward, but if they don't understand how to use digital technology and the instrumentation that comes with it, and if they don't understand the strengths it has in their relationships with their stakeholders, they will fall behind(Domeny, 2017).

In this concern, Toomey (2016) states that digital transformation is a long-term, sustainable process of rapid and sometimes disruptive evolution in society, markets, businesses, and governments. Digital transformation provides new nuances for innovative, creative, and change-loving digital technology users. Hence, digital transformation, though the inexpected challenges it brings, remains significant but needs a certain frame to its success mainly when used for educational purposes. Accordingly, digital leadership is defined as leadership that can determine the direction, influence others, initiate sustainable change through access to information, and build relationships to anticipate changes that are important for schools' success in the future. These fundamental elements will never change but changing times and people's dependence on technology 
require the evolution of practices to create decent and good schools (Prince, 2018; Sheninger, 2014).Digital leadership indicators, according to Doğan (2018), Zhong (2017), Zhong and Zhong (2016) consist of visionary leadership; digital age learning culture; professional development; systemic improvement, and digital citizenship).

\section{Theoretical Framework}

This research framework is adopted from Engelbrecht and Mahembe's research in 2015, which links integrity and ethical leadership with trust. The trust relationship emerged as an important concept in improving employees' welfare and organizational effectiveness. Engelbrecht et al. (2017) developed how the integrity of leaders and ethical leadership can affect trust in leaders and their job members' involvement. Meanwhile, Juracka's research in 2018 tries to test instructional leadership/learning leadership designed to increase teacher work engagement in the curriculum development process (Farris-Berg \& Dirkswager, 2012). Job involvement also shows the need for a more significant leadership role for teachers in increasing their ability to support more substantial learning in the classroom.

Gallante (2015) provides other factors regarding the relationship between instructional leadership and self-efficacy and findings demonstrate a significant relationship between instructional leadership and teacher work engagement. Consequently, educational leadership becomes attractive after being associated with work engagement and being modified by self-efficacy as done by Noormohammadi (2014) who tries to examine the relationship between selfefficacy and teacher reflection, which is thought to improve student learning. Based on some of these studies, the researchers then tried to develop a new type of leadership that is different from the previous type of leadership, namely digital leadership. The investigators add several supporting variables which will later build a more comprehensive framework for teacher reflective practice. Therefore, the research framework used for the purpose of the present research is reflected in Figure 1.

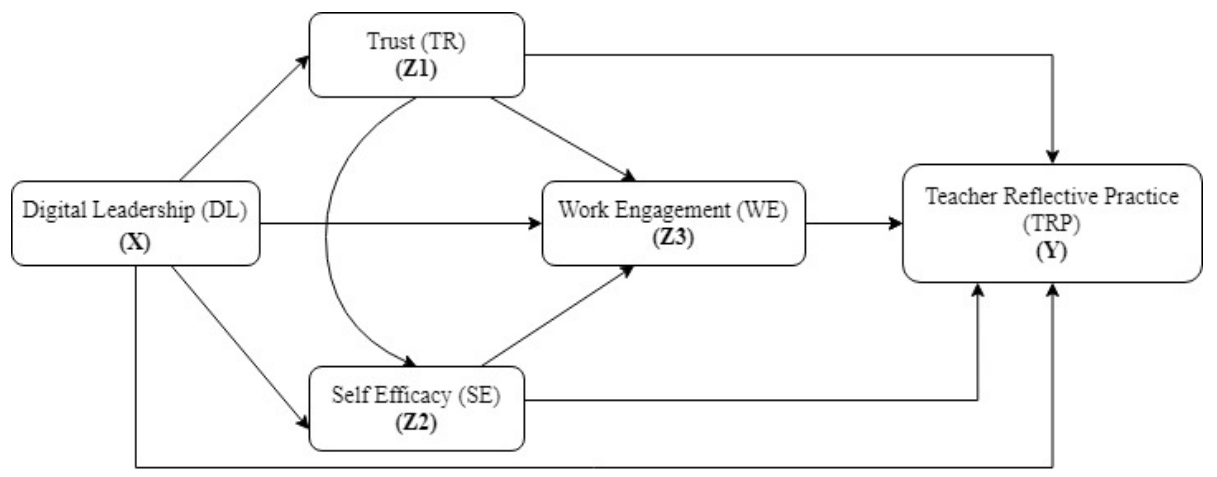

Figure 1.The Conceptual Framework

\section{Methodology}

This research used path analysis with modeling using SEM (AMOS) interpretation. The variables used in this study are: digital leadership, teacher 
trust, efficacy, work engagement, and teacher's practical reflection. The researchers have used a purposive random sampling technique to meet the objectives of this study. 637 ( $\mathrm{N}=340$ females and $\mathrm{N}=297$ males) vocational teachers from a total number of 3727 from Malang Raya (City and District) are selected to participate in this research. Respondents' age ranges from 36 to 45 years with 11-15 years teaching experience. In hope to meet the research objectives, the investigators have used a questionnaire which covers 86 items significantly distributed in response to each variable. The following table displays the studied variables in respect to the endicators used with their corresponding items.

Table 1. Sources of Research Instruments

\begin{tabular}{lllc}
\hline No & \multicolumn{1}{c}{ Variable } & \multicolumn{1}{c}{ Indicator } & No. Question \\
\hline 1 & Teacher's Practical & Practical & $1-6$ \\
& Reflection & Cognitive & $7-12$ \\
& & Learner & $13-15$ \\
& & Metacognitive & $16-22$ \\
& & Critical & $23-29$ \\
\hline 2 & Digital Leadership & Visionary Leadership & $1-2$ \\
& & Digital Age Learning Culture & $3-5$ \\
& & Professional Development & $6-7$ \\
& & Systemic Improvement & $8-10$ \\
& & Digital Citizenship & 11 \\
\hline 3 & Work Engagement & Vigor & $1-6$ \\
& & Dedication & $7-11$ \\
& & Absorption & $12-14$ \\
\hline 4 & Self Efficacy Teacher & EMS = efficacy for & $1-4$ \\
& Bandura's Instrument & motivational strategies & \\
& Teacher Self-Efficacy & ECM = efficacy for classroom & $5-8$ \\
& Scale & management & \\
& & EIS = efficacy for & $9-12$ \\
& & instructional strategies & \\
\hline 5 & Trust & Benevolence & $1-5$ \\
& Variable & Integrity & $6-10$ \\
& Teacher's Practical & Predictability & $11-15$ \\
& Reflection & Competence & $16-20$ \\
\hline
\end{tabular}

The instrument validity test is carried out with 154 respondents with 86 item problems using Pearson Analysis. The results show that the $r$ count for all the designed items are valid with $r=0.133$. The reliability test of the questionnaire is also carried out with the Cronbach Alpha technique. Based on the results of the reliability testing, it shows that the Cronbach alpha number is 0.975 which indicates that the research instruments used to measure the study variables are to a great extent reliable. After testing the validity and reliability of the questionnaire, the prerequisite test or data assumption test is conducted, namely the normality test. The latter is carried out using AMOS, and the Normalization test assessment produces the output as shown in Table 2. 
Table 2. Testing Data Normality with AMOS

\begin{tabular}{lllllll}
\hline Variable & min & max & skew & c.r. & kurtosis & c.r. \\
\hline TR_K & .200 & 15.000 & 1.305 & 13.448 & 11.792 & 60.749 \\
TR_P & .600 & 6.200 & -.177 & -1.829 & -.484 & -2.493 \\
TR_I & .000 & 6.000 & -.392 & -4.038 & -.384 & -1.978 \\
TR_B & .600 & 6.000 & -.240 & -2.475 & -.501 & -2.582 \\
SE_EIS & 1.000 & 6.000 & -.468 & -4.818 & -.507 & -2.611 \\
SE_ECM & .000 & 6.000 & -.687 & -7.078 & .125 & .642 \\
SE_EMS & .000 & 6.000 & -.551 & -5.675 & -.064 & -.329 \\
WE_AB & .000 & 6.000 & -.251 & -2.583 & -.591 & -3.046 \\
WE_DE & .000 & 6.000 & -.602 & -6.206 & -.070 & -.363 \\
WP_VI & .670 & 8.000 & -.422 & -4.349 & -.310 & -1.599 \\
TRP_M & .640 & 6.000 & .045 & .466 & -.740 & -3.810 \\
TRP_L & .670 & 6.000 & .140 & 1.448 & -.623 & -3.210 \\
TRP_C & .670 & 6.000 & .284 & 2.925 & -.462 & -2.380 \\
TRP_P & 1.170 & 6.000 & .058 & .601 & -.725 & -3.736 \\
DL_VL & .000 & 6.000 & -.398 & -4.096 & -.260 & -1.341 \\
DL_DAL & .000 & 6.000 & -.441 & -4.545 & -.046 & -.238 \\
DL_PD & .000 & 7.000 & -.381 & -3.924 & -.115 & -.594 \\
DL_SI & .000 & 6.000 & -.427 & -4.402 & -.209 & -1.076 \\
DL_DC & .000 & 6.000 & -.523 & -5.388 & -.160 & -.825 \\
\hline Multivariate & & & & & 175.667 & 78.474 \\
\hline
\end{tabular}

In table 2, it is known that the value of univariate skewness is not higher than three, and univariate kurtosis does not exceed ten, as suggested by Waluyo (2016). This condition is supported by the value of the critical ratio (C.R) for skewness and kurtosis of each variable which is no higher than \pm 2.58 . Therefore, it is safe to conclude that the data is normally distributed at the univariate level (Haryono, 2016).

\section{Results}

After collecting the intended data, its modeling is processed by SEM (AMOS). The modeling results are reflected in Figure 2. While the effects of calculations are displayed in Table 3. 


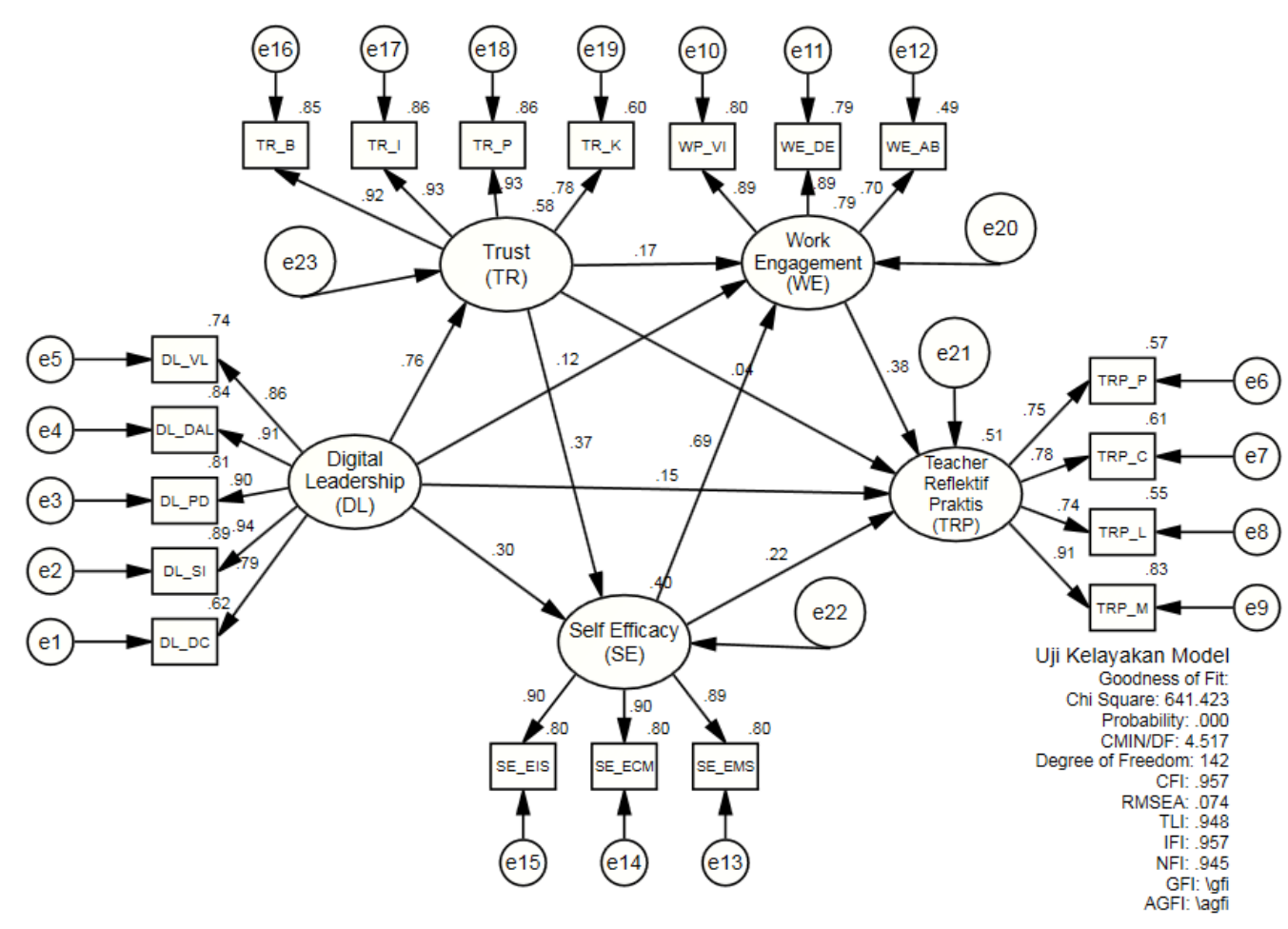

Figure 2. Modelling Using SEM (AMOS)

Table 3. Estimated Regression Weight

\begin{tabular}{llllllll}
\hline & & & Estimate & SE. & CR. & P & Label \\
\hline TR_TOTAL & $<---$ & DL_TOTAL & 0.753 & 0.038 & 19.629 & $* * *$ & par_19 \\
SE_TOTAL & $<---$ & DL_TOTAL & 0.27 & 0.05 & 5.355 & $* * *$ & par_20 \\
SE_TOTAL & $<---$ & TR_TOTAL & 0.334 & 0.05 & 6.619 & $* * *$ & par_22 \\
WE_TOTAL & $<---$ & DL_TOTAL & 0.112 & 0.038 & 2.916 & 0.004 & par_15 \\
WE_TOTAL & $<---$ & TR_TOTAL & 0.157 & 0.04 & 3.966 & $* * *$ & par_16 \\
WE_TOTAL & $<---$ & SE_TOTAL & 0.719 & 0.039 & 18.58 & $* * *$ & par_23 \\
TRP_TOTAL & $<---$ & WE_TOTAL & 0.288 & 0.073 & 3.954 & $* * *$ & par_17 \\
TRP_TOTAL & $<---$ & DL_TOTAL & 0.103 & 0.039 & 2.669 & 0.008 & par_18 \\
TRP_TOTAL & $<---$ & SE_TOTAL & 0.17 & 0.065 & 2.613 & 0.009 & par_21 \\
TRP_TOTAL & $<---$ & TR_TOTAL & 0.025 & 0.04 & 0.626 & 0.531 & par_24 \\
DL_SI & $<---$ & DL_TOTAL & 1.087 & 0.038 & 28.664 & **** & par_1 \\
\hline *TR $=$ Trust & & & & & & \\
*SE = Self Efficacy & & & & & & \\
*WE = Work Engagement & & & & & \\
*DL = Digital Leadership & & & & & \\
*TRP = Teacher Reflective Practice & & & & & & \\
\hline
\end{tabular}

From the results of the above output (Table 3), it can be concluded that there is one item variable that doesn't fit, namely TR to TRP with a significance value of 0.531 or $>0.05$. This finding indicates that the variable does not directly affect the model used. The model will become fit by removing the factors that do not fit as shown in Figure 3. 


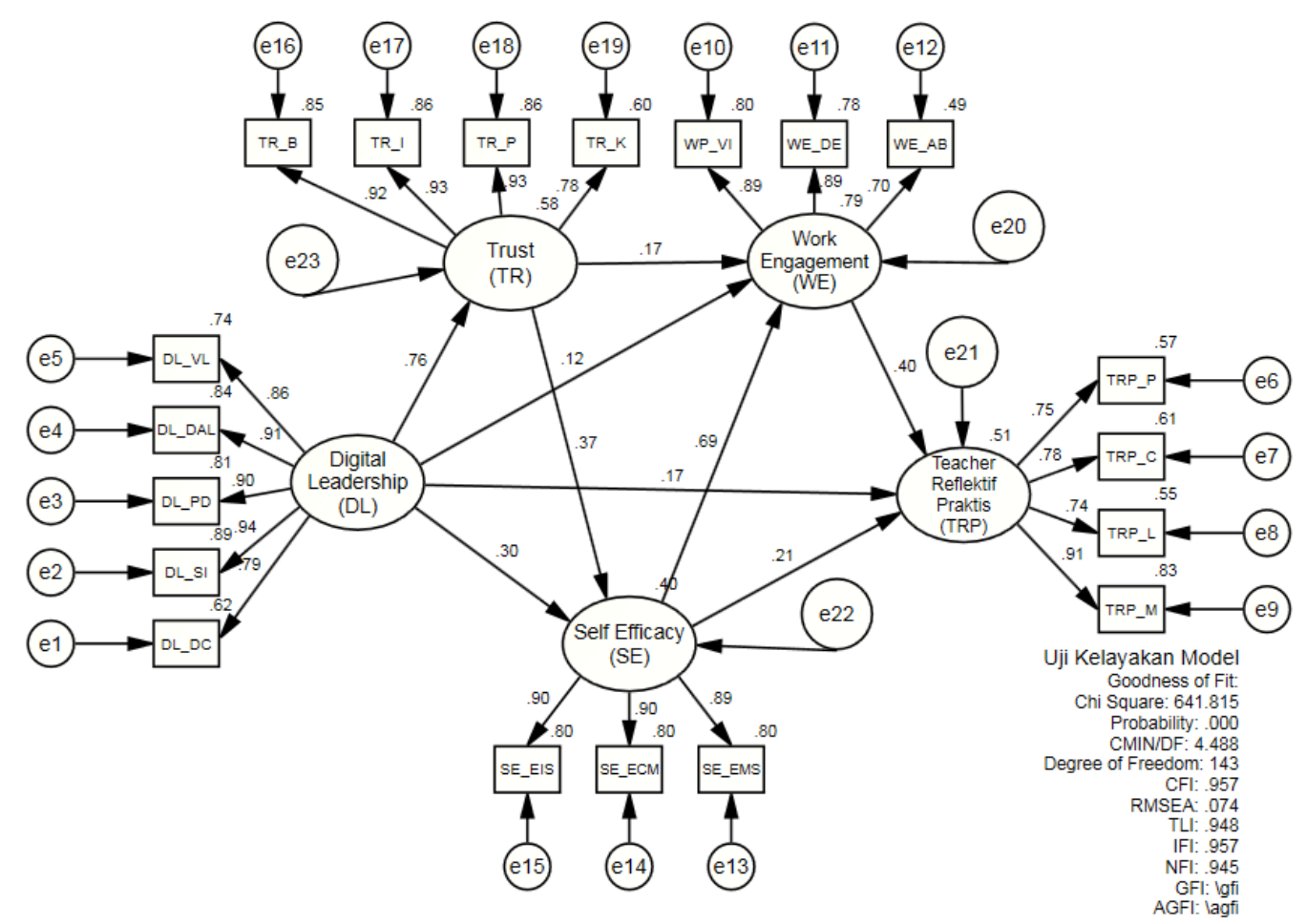

Figure 3. Model Fit

In order to clearly understand the above findings, the researchers find it significant to reflect the same data as follows:

Table 4. Standard Regression Weights

\begin{tabular}{llllllll}
\hline & & & Estimate & SE. & CR. & P & Label \\
\hline TR_TOTAL & $<---$ & DL_TOTAL & 0.754 & 0.038 & 19.634 & $* * *$ & Par_19 \\
SE_TOTAL & $<---$ & DL_TOTAL & 0.27 & 0.05 & 5.342 & $* * *$ & Par_20 \\
SE_TOTAL & $<---$ & TR_TOTAL & 0.334 & 0.05 & 6.632 & $* * *$ & Par_22 \\
WE_TOTAL & $<---$ & DL_TOTAL & 0.111 & 0.038 & 2.888 & 0.004 & Par_15 \\
WE_TOTAL & $<---$ & TR_TOTAL & 0.159 & 0.04 & 4.021 & $* * *$ & Par_16 \\
WE_TOTAL & $<---$ & SE_TOTAL & 0.719 & 0.039 & 18.575 & $* * *$ & Par_23 \\
TRP_TOTAL & $<---$ & WE_TOTAL & 0.299 & 0.071 & 4.222 & $* * *$ & Par_17 \\
TRP_TOTAL & $<---$ & DL_TOTAL & 0.117 & 0.032 & 3.684 & $* * *$ & Par_18 \\
TRP_TOTAL & $<---$ & SE_TOTAL & 0.167 & 0.065 & 2.569 & 0.01 & Par_21 \\
DL_SI & $<---$ & DL_TOTAL & 1.087 & 0.038 & 28.66 & $* * *$ & Par_1 \\
\hline
\end{tabular}

From the output in Table 4, it can be read that all values are significant $<0.05$ and hence the model is fit. 
Table 5. Estimated Fit Model Calculations Standardized Regression Weights: (Group Number 1 - Default Model)

\begin{tabular}{llll}
\hline & & & Estimate \\
\hline TR_TOTAL & $<---$ & DL_TOTAL & 0.759 \\
SE_TOTAL & $<---$ & DL_TOTAL & 0.301 \\
SE_TOTAL & $<---$ & TR_TOTAL & 0.371 \\
WE_TOTAL & $<---$ & DL_TOTAL & 0.12 \\
WE_TOTAL & $<---$ & TR_TOTAL & 0.17 \\
WE_TOTAL & $<---$ & SE_TOTAL & 0.694 \\
TRP_TOTAL & $<---$ & WE_TOTAL & 0.397 \\
TRP_TOTAL & $<---$ & DL_TOTAL & 0.168 \\
TRP_TOTAL & $<---$ & SE_TOTAL & 0.214 \\
DL_SI & $<---$ & DL_TOTAL & 0.942 \\
\hline
\end{tabular}

The regression weight output results can be seen in Table 5 as the role of the standardized coefficient relationship of one variable to another. That is to say, this standardized coefficient has an expected value from $0-1$, in which is now possible to compare which one has a more significant role. From table 5, it is possible to say that:

The Role of Digital Leadership to Trust is 0.759;

The Role of Digital Leadership to Self-Efficacy is 0.301;

The Role of Digital Leadership to Work Engagement is 0.120;

The Role of Digital Leadership to Teacher Reflective Practice is 0.168;

The Role of the Trust to Self-Efficacy is 0.371;

The Role of Trust to Work Engagement is 0.170;

The Role of Teacher Efficacy to Work Engagement is 0.694;

The Role of Self Efficacy to Teacher Reflective Practice is 0.214; and

The Role from Work Engagement to Teacher Reflective Practice is 0.397.

Based on the above results, a path diagram is obtained as shown in Figure 4.

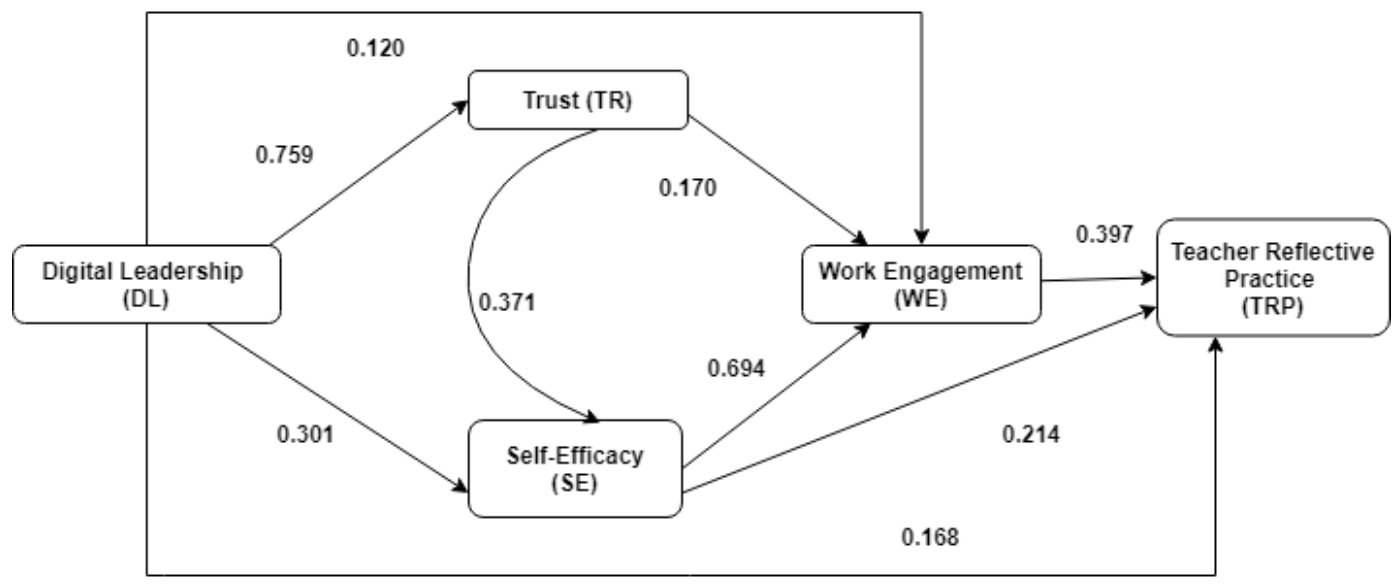

Figure 4. Model Fit Results in the Form of a Path Diagram

In Table 5, square multiple correlations show the effective contribution of independent variables to the dependent variable. If we look at the output in SPSS, this value is indicated by $\mathrm{R}$ Square's value. 
Table 6. Squared Multiple Correlation Model Fit 2

\begin{tabular}{ll}
\hline & Estimate \\
\hline TR_TOTAL & .576 \\
SE_TOTAL & .398 \\
WE_TOTAL & .794 \\
TRP_TOTAL & .508 \\
\hline
\end{tabular}

As shown, the effective contribution of DL to TR is $0.576(57.6 \%)$ while the effective contribution of DL and TR to SE is 0.398 (39.8\%). The effective participation from DL, TR and SE to WE is $0.794(79.4 \%)$, whereas the effective contribution from DL, TR, SE, and WE to TRP is 0.508 (50.8\%).

\section{Discussion}

The Principal's digital leadership role in vocational education provides fresh air and new nuances in the school educational system. As one of the educations that pays close attention to technological change, vocational strives to prepare its graduates to have competencies that are always adaptive to technological changes. The role of vocational teachers as educators is also required to quickly adjust to technological changes, both in learning media and as special skills/competencies. In this regard, Mok \& Moore (2019) emphasis that the teacher's role is crucial in changing the learning situation by making students more involved in the learning process. The results showed that the factors that influence teachers' positive reflective actions begin specifically with the principal's digital leadership role. This finding is in line with D. Van Niekerk research (2015),in which technology integration will not succeed without the principal who encourages the change process. Consequently, the role of the Principal as a leader greatly influences the teacher reflection process.

The present study results contribut in strengthening the role of the principal in technology integration and teachers' reflective actions. This study also confirms that digital leadership is an essential factor both directly and indirectly influencing and encouraging teachers to work effectively as expected by Drewniak \& Karaszewski (2016). In parallel, Chou, Shen, Hsiao and Shen (2019) claim that school systems and culture become attractive when technology is present. Digital leadership today is needed and has become the fashion that current school principals must have in the future. Principals are responsible for instructional leadership in schools by facilitating the integration of teacher technology in the classroom. More importantly, the Principal administrator's active involvement as the principal administrator is another factor in the successful application of technology in the teaching and learning process (Doğan, 2018; Prince, 2018).

This study also looks at the Principal's digital leadership role that is felt directly by the teacher. The obtained results show that digital leadership goal in fostering teacher confidence give the highest direct contribution with 0.759 . This means that teacher trust in leaders provides positive encouragement to teachers in the self-development process. This result aligns with Ünal and the followers research (2015), which states that technology continues to dominate culture in all 
areas of life. School leaders' ability to adapt to technological developments is crucial, so school leaders need to consider themselves as digital leaders to lead teachers and students towards the technological era. Based on the study results, it is significant to mention that the trust variable strengthens the practice of teacher reflection indirectly through the efficiency and work involvement variables. There is a contribution of 0.249 which means that teacher trust in leaders is needed in teacher self-development to reflect on the learning outcomes (Engelbrecht et al., 2017).

It can also analogize from the current study that teacher trust will grow when digital leaders and teachers interact in an intensive and quality relationship. Moreover, prompt treatment, motivation, and support facilities from digital leaders show that teachers tend to be motivated and reciprocate with equal attention. Another variable that mediates and makes a positive contribution to teacher reflective practice is self-efficacy. In this respect, the results suggest that there is a reasonably healthy relationship between digital leadership and selfefficacy. Besides, the motivation given by the Principal has a positive impact on increasing the effectiveness of teachers in reflecting on learning in class. The direct contribution of digital leadership to teacher efficacy is 0.301 , and the indirect effect on teacher reflection practice is 0.281 which gives 0.582 as the total impact of this factor. This influence is quite considerable because digital leadership has a professional development factor where leaders must provide facilities and permit teachers to use technology. Teachers need to get teaching materials, modify them, and present them to be fun learning for students. Leadership and self-efficacy are undoubtedly indispensable in building effective teachers (Doğan, 2018).

Teachers with high self-efficacy always involve all students, both smart and weak (Harris, Caldwell \& Longmuir, 2013). Teachers who have high efficacy can create a pleasant atmosphere and understand all students' needs, thus making them ready and systematically easy to adapt to the environment and find their learning needs (Doğan, 2018). Digital leadership and trust in self-efficacy contributed with $39.8 \%$. To this end, self-efficacy is influenced by leadership style and trust. Trust and decision making are other factors related to leadership abilities. If the teacher feels that the principal cannot make the right decision, the teacher will not trust them (Harris et al., 2013). Yet, when teachers finds a sense of belonging to the class, they will be more involved and committed to being more engaged in improving classroom learning (Farris-Berg \& Dirkswager, 2012).

The relationship between teacher trust and work engagement in this study reasonably provides a good contribution value of 0.12 for direct connections and 0.533 for indirect links. It is proved that there is an influence between digital leadership and direct work engagement. This result is supported by Bellingham (2013) who states that leaders can give teachers the freedom to provide support and initiative through responsibility and authority to foster work engagement in their work (Juracka, 2018). Brown, Czerniewicz, Huang \& Mayisela (2016) also find a positive correlation between digital leadership and job dedication, which is a significant work engagement element (Men, 2015; Minghui et al., 2018). 
Through regression analysis, it has been confirmed that leadership has a positive relationship with work engagement. Research has found that teachers tend to have higher job engagement when they think their leader can provide full support. Hence, this study concluded that the useful contribution of leadership factors, trust, and teacher efficacy to teacher work engagement is $79.4 \%$.

Through the work engagement factor, leaders can manage good relationships with teachers because emotional concepts are among the core indicators that reflect the quality of teacher work life. This indicator considers significant variations in job predictions and their organizational outcomes, such as teaching performance, problem-solving, organizational commitment, and job satisfaction (Brown et al., 2016; Den Hartog \& Belschak, 2012; Tripney et al., 2013). Furthermore, other researchers also show that work engagement has a significant and a positive correlation with self-efficacy (Hoigaard, Giske \& Sundsli, 2012). work engagement can mediate between social support and selfefficacy. Previous studies have also shown that work engagement changes are closely related to self-efficacy (Minghui et al., 2018; Zee \& Koomen, 2016). In this study, through the trust variable, the relationship between digital leadership and self-efficacy is met with $39.8 \%$. Meanwhile, through trust and self-efficacy variables, the relationship between digital leadership and work engagement is $79.4 \%$. It also shows a close relationship between trust, self-efficacy, and work engagement.

\section{Conclusion}

This study aims to examine the relationship between principal digital leadership and its effect on teachers' reflective practice skills. The mediator variables that have an influence or contribution are trust, self-efficacy, and work involvement. This study suggests a new relationship model between the principal's digital leadership and mediator variables on teachers' reflective ability to develop learning. Put differently, this study emphasizes the principal's digital leadership role in vocational teachers' perceptions of their ability to reflect on their learning practices. As far as the first research question is concerned, findings show that there is a relationship between digital leadership, teacher trust, efficacy, work engagement, and reflective teacher practice. Concerning the second research question, findings reveal that the variables of trust, self-efficacy, and teacher work engagement are moderating variables between digital leadership and teacher's reflective practices. The practical contribution of the digital leadership variable to teacher trust is $57.6 \%$, while the effective participation of digital leadership and teacher trust in teacher effectiveness is $39.8 \%$. The significant contribution of digital leadership, trust, and self-efficacy to work engagement is $79.4 \%$.

Throughout this study, interesting results are gathered on the fact that the new relationship is a direct contribution of digital leadership to work engagement with a magnitude of 0.120 , and a direct relationship between digital leadership and teacher reflective practice is of 0.168 . Although the value is not that large, this relationship positively impacts teachers' reflective actions. Teachers feel motivated and excited to reflect on their learning by leaders who have digital 
characters. Assimilating others research results with the findings gathered from the present attempt would generate another move towards better outcomes.

\section{Acknowledgment}

The investigators wish to thank LPDP as the Indonesian Scholarship and Research Funding Service help in collecting the intended data, and without their assistance, this research won't be possible.

\section{References}

Barni, D., Danioni, F., \& Benevene, P. (2019). Teachers' self-efficacy: The role of personal values and motivations for teaching. Frontiers in Psychology, 10, 1-7. https://doi.org/10.3389/fpsyg.2019.01645

Bassot, B. (2016). The Reflective Practice Guide: An interdisiplinary approach to critical reflection. https:// doi.org/10.4324/9781315768298

Beetham, H., \& Sharpe, R. (2013). Rethinking pedagogy for a digital age: Designing for 21st century learning ( $2^{\text {nd }}$ ed.). New York: Routledge.

Bellingham, R. (2013). Ethical Leadership Rebuilding Trust in Corporations. Journal of Chemical Information and 53. https://doi.org/10.1017/CBO9781107415324.004

Bolton, G. (2015). Write to learn : reflective practice writing. Sage Publications, 2(12), 752754. https://doi.org/10.1093/innovait/inp105

Brown, C., Czerniewicz, L., Huang, C.-W., \& Mayisela, T. (2016). Curriculum for Digital Education Leadership : A Concept Paper. Commonwealth of Learning.

Chou, C. M., Shen, C. H., Hsiao, H. C., \& Shen, T. C. (2019). Factors influencing teachers' innovative teaching behaviour with information and communication technology (ICT): the mediator role of organizational innovation climate. Educational Psychology, 39(1), 65-85. https://doi.org/10.1080/01443410.2018.1520201

Den Hartog, D. N., \& Belschak, F. D. (2012). Work Engagement and Machiavellianism in the Ethical Leadership Process. Journal of Business Ethics, 107(1), 35-47. https:// doi.org/10.1007/s10551-012-1296-4

Doğan, İ. (2018). Examination of the Technology Leadership Self-Efficacy Perceptions of Educational Managers in terms of the Self-Efficacy Perceptions of Information Technologies (Malatya Province Case). Participatory Educational Research, 5(2), 51-66. https://doi.org/10.17275/per.18.9.5.2

Domeny, J. (2017). The relationship between digital leadership and digital implementation in elementary schools (Doctoral dissertation). Southwest Baptist University.

Drewniak, R., \& Karaszewski, R. (2016). Factors Strengthening the Involvement of Employees and Their Role in Knowledge Management in an Enterprise: An Empirical Evidence from Polish Companies, 7(5), 432-445.

Engelbrecht, A. S., Heine, G., \& Mahembe, B. (2017). Integrity, ethical leadership, trust and work engagement. Leadership and Organization Development Journal, 38(3), 368-379. https://doi.org/10.1108/LODJ-11-2015-0237

Engelbrecht, A. S., \& Mahembe, B. (2015). The influence of integrity and ethical leadership on trust in the leader. Management Dynamics, 24(1).

Farris-Berg, K., \& Dirkswager, E. J. (2012). Trusting teachers with school success: What happens when teachers call the shots. Lanham, MD: R\&L Education.

Gallante, P. E. (2015). Principal Leadership Behaviors and Teacher Efficacy. Walden University ScholarWorks, 1-136.

Harris, J., Caldwell, B., \& Longmuir, M. F. (2013). Literature review : A culture of trust enhances performance. In Australian Institute for TEaching and School Leadership 
(1 ${ }^{\text {st }}$ ed.). Melbourne: Australian Institute for Teaching and School Leadership (AITSL).

Haryono, S. (2016). Metode SEM Untuk Penelitian Manajemen AMOS, LISREL, PLS (1 ${ }^{\text {st }}$ ed.). Jakarta: PT. Intermedia Personalia Utama.

Hoigaard, R., Giske, R., \& Sundsli, K. (2012). Newly qualified teachers' work engagement and teacher efficacy influences on job satisfaction, burnout, and the intention to quit. European Journal of Teacher Education, 35(3), 347-357. https://doi.org/10.1080/02619768.2011.633993

Jachowicz, L. M. (2016). Trust, leadership, and communication satisfaction in higher education: Faculty perceptions of their department and division chairs.

Juracka, S. (2018). Employee Engagement Through the Instructional Leadership Team (Doctoral dissertations, National Louis University). Retrieved from https://digitalcommons.nl.edu/diss/326\%

Kalkan, Ü., Aksal, F. A., Gazi, Z. A., Atasoy, R., \& Dağll, G. (2020). The Relationship Between School Administrators ' Leadership Styles, School Culture, and Organizational Image. Sage Open, 1-15. https://doi.org/10.1177/2158244020902081

Kamdi, W. (2014). Kinerja guru smk: analisis beban kerja dan karakteristik pembelajaran. Teknologi Dan Kejuruan, 37(1), 1-12.

Loebbecke, C., \& Schepers, S. (2020). European Innovation Policy and Political Processes. In R. Dewenter, J. Haucap \& C. Kehder (Eds.), Wettbewerb und Regulierung in Medien, Politik und Märkten, pp. 99 - 114. Festschrift für Jörn Kruse zum 65.

McCarty, K. A. (2013). The Relationship Between Special Education Teachers' Sense of Teacher Efficacy and their Intent to Leave (Doctoral Dissertation). Azusa Pacific University, California.

McKeown, S. (2015). Digital leaders Survey. In BCS -Enabling the Information Society, 2015 (21). https:// doi.org/10.12968/sece.2015.21.10

Men, L. R. (2015). Employee Engagement in Relation to Employee-Organization Relationships and Internal Reputation: Effects of Leadership Communication. Public Relations, 9. https:// doi.org/1942-4604

Mineo, D. L. (2014). The Importance of Trust in Computer Security. IFIP International Conference on Trust Management - IFIPTM 2014: Trust Management, 8, 1-12. https://doi.org/10.1007/978-3-662-43813-8_1

Minghui, L., Lei, H., Xiaomeng, C., \& Potmešilc, M. (2018). Teacher Efficacy , Work Engagement, and Social Support Among Chinese Special Education School $\begin{array}{lllll}\text { Teachers. } & \text { Frontiers in Psychology, 9, }\end{array}$ https://doi.org/10.3389/fpsyg.2018.00648

Miovska-Spaseva, S. (2016). The Educational Theory of John Dewey and its Influence on Educational Policy and Practice in Macedonia. Espacio, Tiempo y Educación, 3(2), 207. https://doi.org/10.14516/ete.2016.003.002.009

Mok, M. M. C., \& Moore, P. J. (2019). Teachers \& self-efficacy. Educational Psychology, 39(1), 1-3. https:// doi.org/10.1080/01443410.2019.1567070

Nie, Y. (2015). The Teacher Efficacy Scale: A Reliability and Validity Study.

Nie, Y., Lau, S., \& Liau, A. K. (2012). The Teacher Efficacy Scale: A reliability and validity study. The Asia-Pacific Education Researcher, 21(2), 414-421.

Niekerk, D. Van. (2015). Prepared for the 2015 Global Assessment Report on Disaster Risk Reduction: Retrospective Assessment of Progress in Disaster Risk Governance.

Niekerk van, E. J., \& Wyk van, M. M. (2014). Staff's perceptions of vision and long term principal leadership in South African schools: An exploratory study. Mediterranean Journal of Social Sciences, 5(4), 406-414. 
https://doi.org/10.5901/mjss.2014.v5n4p406

Noormohammadi, S. (2014). Teacher Reflection and its Relation to Teacher Efficacy and Autonomy. Procedia - Social and Behavioral Sciences, 98, 1380-1389. https://doi.org/10.1016/j.sbspro.2014.03.556

Osifo, O. C. (2016). Improving Trust Through Ethical Leadership: Moving Beyond the Social Learning Theory To a Historical Learning Approach. Journal of Media Critiques, 2(8), 11-24. https://doi.org/https://doi.org/10.17349/jmc116201

Prince, K. A. (2018). Digital leadership: transitioning into the digital age (Doctoral dissertation, James Cook University, Australia). https://doi.org/10.25903/5d2bdd672c0e5

Reza, M., \& Sarab, A. (2016). Teachers as Reflective Practitioners : A Survey on Iranian English Teachers ' Reflective Practice Survey on Iranian English Teachers '. Journal Of Teaching Language Skills (JTLS), 7(4), 57-86.

Richardson, J. W., Bathon, J., Flora, K. L., \& Lewis, W. D. (2012). NETS•A scholarship: A review of published literature. Journal of Research on Technology in Education, 45(2), 131-151. https:// doi.org/10.1080/15391523.2012.10782600

Salicru, S. (2015). LEADERSHIP 2050: Critical Challenges, Key Contexts and Emerging Trends What kind of leaders will the world need over the next thirty-five years?.

Schön, D. A. (1983). The Reflective Practitioner: How Professionals Think in Action. New York: Basic Books. https:/ / doi.org/10.1177/14733250090080010802

Sheninger, E. (2014). Pillars of Digital Leadership 7 Pillars of Digital Leadership in Education.

Slade, M. L., Burnham, T., Catalana, S. M., \& Waters, T. (2019). The Impact of Reflective Practice on Teacher Candidates' Learning. International Journal for the Scholarship of Teaching and Learning, 13(2), 1-8. https://doi.org/10.20429/ijsotl.2019.130215

Toomey, M. (2016). ACS Briefing Digital Transformation. Australia: Infonomics Pty.

Tripney, J., Hombrados, J., Newman, M., Hovish, K., Brown, C., \& Steinka-fry, K. (2013). Technical and Vocational Education and Training (TVET) Interventions to Improve the Employability and Employment of Young People in Low- and Middle- Income Countries: A Systematic Review. In Campbell systematic reviews, 9(1), pp. 1-171. https://doi.org/10.4073/csr.2013.9

Ünal, E., Uzun, A. M., \& Karataş, S. (2015). Ispitivanje samoučinkovitosti ravnatelja u upravljanju tehnologijom. Croatian Journal of Education, 17(1), 195-215. https://doi.org/10.15516/cje.v17i1.968

Waluyo, M. (2016). Mudah Cepat Tepat Penggunaan Tools Amos Dalam Aplikasi (SEM). UPN "Veteran" Jatim.

Want, A. C. Van Der, Brok, P. Den, Beijaard, D., Brekelmans, M., Claessens, L. C. A., \& Pennings, H. J. M. (2019). Professional Development in Education The relation between teachers' interpersonal role identity and their self-efficacy, burnout and work engagement. Professional Development in Education, 45(3), 488-504. https:// doi.org/10.1080/19415257.2018.1511453

Zee, M., \& Koomen, H. M. Y. (2016). Teacher Self-Efficacy and Its Effects on Classroom Processes, Student Academic Adjustment, and Teacher Well-Being: A Synthesis of 40 Years of Research. Review of Educational Research, 86(4), 981-1015. https:// doi.org/10.3102/0034654315626801

Zhong, L. (2017). Indicators of Digital Leadership in the Context of K-12 Education. Journal of Educational Technology Development and Exchange, 10(1), 27-40.

Zhong, L. (2016). The Effectiveness of Digital Leadership at K-12 Schools in Mississippi Regarding Communication and Collaboration During CCRS Implementation (Doctoral dissertation, University of Southern Mississippi). 